\title{
The association of migration experiences on the self-rated health status among adult humanitarian refugees to Australia: an analysis of a longitudinal cohort study
}

\author{
Alison Dowling ${ }^{1 *}\left(\mathbb{D}\right.$, Joanne Enticott ${ }^{1,2}$, Marina Kunin ${ }^{1}$ and Grant Russell ${ }^{1}$
}

\begin{abstract}
Background: Refugees are potentially at an increased risk for health problems due to their past and current migration experiences. How migration factors shape refugee health is not well understood. We examined the association between migration factors and the self-rated general health of adult humanitarian refugees living in Australia.

Methods: We analyzed the first three waves of data from the 'Building A New Life In Australia' longitudinal survey of 2399 humanitarian refugees resettled in Australia. The study outcome was self-rated health measured by the 36Item Short Form Health Survey. Predictors were migration process and resettlement factors. We used generalized linear mixed models to investigate the relationship between predictor and outcome variables.

Results: Poor general health persisted among this refugee population at high levels throughout the three-year follow-up. At baseline, 35.7\% (95\% Cl: 33.8-37.7\%) of the study population reported poorer general health. Female gender, increasing age and post-migration financial stressors were positively associated with poorer general health. Having a university degree and absence of chronic health conditions were seemingly protective against declining general health (OR: 0.50; 95\% Cl: 0.65-1.81 and OR: 0.15, 95\% Cl: 0.09-1.04, respectively).

Conclusion: Our results show that there is persisting high prevalence of poorer general health among adult refugees across the initial years of resettlement in Australia. This finding suggests unmet health needs which may be compounded by the challenges of resettlement in a new society, highlighting the need for increased clinical awareness of this sustained health burden to help inform and prepare refugee health care and settlement service providers.
\end{abstract}

Keywords: Refugees, Humanitarian, Self-rated health, General health, Migration, Resettlement, Longitudinal, Building A new life in Australia

\section{Background}

In 2017, almost 68.5 million people have been forcibly displaced from their homes, the largest number ever recorded. Of these, 25.4 million were recognised as refugees, while 3.1 million were asylum seekers [1]. Refugees are often unable to return to their home country for fear of death or persecution and may be offered resettlement

\footnotetext{
* Correspondence: alison.dowling@monash.edu

${ }^{1}$ Department of General Practice, School of Primary Health Care, Monash University, Melbourne, Australia

Full list of author information is available at the end of the article
}

in a third country [1], such as Australia, which offers resettlement to 18,750 refugees and others with humanitarian needs each year [2]. Refugees who are accepted for resettlement are among the most vulnerable groups in our society in terms of risk for poor health due to their past and current experiences [3]. Therefore, it is important for resettlement nations to understand the long-term health needs and settlement prospects of this vulnerable and ever-growing population, so that timely and appropriate supports can be provided [4-9]. However, the extent to which migration factors shape the

(c) The Author(s). 2019 Open Access This article is distributed under the terms of the Creative Commons Attribution 4.0 International License (http://creativecommons.org/licenses/by/4.0/), which permits unrestricted use, distribution, and reproduction in any medium, provided you give appropriate credit to the original author(s) and the source, provide a link to the Creative Commons license, and indicate if changes were made. The Creative Commons Public Domain Dedication waiver (http://creativecommons.org/publicdomain/zero/1.0/) applies to the data made available in this article, unless otherwise stated. 
long-term health of resettling refugees is not well understood.

Some of this knowledge gap can be attributed to methodological limitations in the current research [3]. To date, the bulk of the research investigating the health of resettling refugees has largely employed a cross-sectional methodology to investigate mental health outcomes, using a variety of quantitative measurement tools [3]. This has meant that information is not available on the full spectrum of the refugee health burden, but that refugee health data is often conflicting and difficult to interpret and compare and can provide only a 'snapshot' of a single moment in the refugee resettlement experience [3]. Longitudinal approaches that collect self-rated general health information from refugees may be one way to overcome this knowledge gap.

Self-rated general health (SRGH) is the subjective measurement of an individual's general health and is based upon a simple question in which respondents are asked to rate their general health during the past 4 weeks on a scale ranging from "excellent" to "very poor" [10]. Despite its simplicity, SRGH has been found to be an unusually strong predictor of mortality, morbidity and health service utilization [10]. For example, a recent meta-analysis found that those who report "poor" health have a twofold higher risk of all-cause mortality relative to those who report "excellent" health [10]. In ways that are still unclear, SRGH integrates biological, mental, social and functional aspects of a person, including individual and cultural beliefs and health behaviours $[11,12]$. Therefore, SRGH can capture information about an individual's health and well-being that more objective measures cannot. Given that refugees have been shown to rate their health as fair-to-poor more frequently than other immigrants after arrival in a developed country [13], we propose that SRGH may be a valuable health index for use among refugee populations; especially given that SRGH has proven reliability and validity among refugee populations [3].

To address the empirical gap in the refugee health literature, this present study examined the association between self-rated general health and pre- and postmigration experiences of resettled adult humanitarian refugees living in Australia. We used the first three years of data from the Australian Government's 'Building A New Life in Australia' (BNLA) longitudinal survey. Other analyses of the BNLA survey have been published [4, 14-17], but none have investigated the impact of migration on the self-rated health of the BNLA respondents. To our knowledge, this is the first study of its kind to use the described methodological approach to investigate the health of resettled refugees. It is anticipated that the knowledge that emerges from this study will lead to recommendations for resettlement services that might be more effective than those currently in place. The aim of our study is to gain insight into the impact of migration on the long-term general health of refugees during their initial resettlement in Australia.

\section{Methods}

\section{Data sources}

We conducted a secondary examination of the first three waves of the BNLA study, collected from October 2013 to March 2016. The BNLA is a five-year national study (2013-2018) conducted by the Australian Government's Institute of Family Studies to examine how humanitarian refugees settle into a new life in Australia [18]. The Australian Federal Government's Department of Social Services (DSS) funded the BNLA study. Further information about the BNLA study design can be found in publicly available documents [18].

\section{Ethics approval}

The BNLA study received ethics approval by the Australian Institute of Family Studies Human Research Ethics Committee. De-identified BNLA data is accessible by authorized researchers who have obtained permission from the Australian Department of Social Services. This permission was obtained by study authors AD, JE and GR. Ethics exemption to use the data was granted by the Monash University Research Ethics Committee (see Additional file 1).

\section{Study population and sampling}

The BNLA cohort comprised of individuals aged 15 years and over who had been granted a permanent humanitarian visa by the Australian Government in the 3-6 months preceding the baseline BNLA study [18]. Eligible participants were identified via the Australian Department of Immigration and Border Protection settlement database from eleven locations around Australia to ensure adequate sample size. Migrating Units (MU) were the primary sampling units for the study and consisted of principal applicants (PA) and secondary applicants (SA). Principal Applicants were the lead participant for the study, and were the initial individuals contacted for participation. Secondary Applicants comprised other members of the Migrating Unit listed on the Principal Applicant's visa application. The Principal Applicant had to consent to participating before SAs could be invited to do so [18]. A total of 2031 out of 4035 eligible Principal Applicants were contacted and 1509 Principal Applicants and 890 Secondary Applicants completed baseline interviews. The respondents are from 35 different countries and speak 50 different languages and at baseline, aged between 15 and 83 years [18]. 


\section{Data collection}

The first three waves of 'Building A New Life in Australia' data were obtained using either home visits (Waves 1 and 3) or telephone interviews (Wave 2). The BNLA written survey was translated into 14 different languages for Wave 1. A total of 19 languages were covered for the survey with the aid of interpreters [18].

\section{Variable selection}

A number of predictor variables were selected from the BNLA survey and related to migration and resettlement, socio-demographics and the presence/absence of chronic conditions.

A conceptual framework used for this study was informed by Cross-Denny \& Robinson's social determinants of health model [19]. The Cross-Denny \& Robinson's model uses five key areas or determinants that are particularly relevant for oppressed and marginalised populations. We added "Political, Socio-Economic" category to encompass the significant associations between structural/political factors (such as spent time in immigration detention centres, migration pathway) and poorer health among refugees. Our adapted model includes six key determinants of refugee health and 25 candidate variables (See Fig. 1). A review of the literature reporting predictors of refugee health outcomes informed the selection of candidate variables from the BNLA dataset to populate the social determinant of health model.

\section{Outcome measures}

Factors relating to migration and resettlement in host country and health were measured by the 'Building A New Life In Australia' self-report survey [18]. Our principal outcome variable was self-rated general health and used the question "Overall, how would you rate your health during the past 4 weeks?" selected from the SF-36 [20]. The SF-36 is a generic measure of health status with reliability and validity among refugee populations [3]. The BNLA survey uses a 6-point Likert response scale ("Excellent" to "Very Poor"). For our study, we use a dichotomous variable comprising of two health response categories of "Excellent-Good" and "Fair-Very Poor". The decision regarding the creation of the two response categories was based on a review of the literature, which confirmed that our dichotomous response groupings were appropriate [21].

\section{Statistical analysis}

Analysis included descriptive and generalized linear mixed modelling (GLMM). Descriptive statistics describe the overall characteristics of the sample population at baseline, such as socio-demographics, migration experiences using means and standard deviations (SDs) for continuous variables and frequencies and percentages for categorical variables. All analyses used adjusted weights, provided by the BNLA project. Variables with over $10 \%$ missing data at baseline were excluded if we were unable to account for the missing data. Only variables asked across all three waves were included in the analysis. Continuous outcome variables, such as age, were transformed into categorical variables. All analyses were done with Stata/SE 15.1 [22].

To examine the relationships longitudinally between outcomes and predictor variables, GLMM were used. As the BNLA data involved multi-level, clustered sampling, GLMMs accounted for inter-individual random effects between different 'migrating unit' clusters (ie. the families) and individual participants, as well as intra-individual fixed effects or the repeated measures within individual participants. GLMMs were appropriate for our analysis as ordinary linear models are unable to handle clustered data. Variable selection for the final models occurred in several steps. Firstly, univariate regressions were used to examine associations between baseline candidate variables and outcome variables, with variables retained at $p<0.1$. In the second step, collinearity was then examined using Pearson's correlation coefficient to remove highly correlated variables from the final model. In this study, one candidate variable was selected from two or more correlated variables when $r>0.5$. The third step involved examining associations between candidate variables and outcome variables using multivariate GLMM. A variable denoting study time: 'wave' was included in these models. Variable at $p<0.1$ were retained. In the last step, candidate variables were modelled over 1000 bootstrap samples at $95 \%$ resampling for the data set. Candidate variables were retained in final models if they were identified as significant $(p<0.05)$ in 1000 bootstraps over $50 \%$ of the time.

\section{Role of the funding source}

The BNLA is funded by the Australian Government's Department of Social Services and were not involved in the preparation of this manuscript or the analyses reported.

\section{Results \\ Demographics}

At baseline, 2399 individuals took part in the BNLA study. The mean age was 35.5 years $(\mathrm{SD}=13.9)$ and $54.0 \%$ were male. Over half of the participants $(61.0 \%)$ were married or partnered and nearly half (45\%) were born in the Middle East. Almost a third (32.5\%) had little to no schooling upon arrival to Australia and $12.1 \%$ held university qualifications. Before coming to Australia, 33.6\% could speak English 'very well-well'. A vast majority (88.9\%) of participants had exposure to one or more traumatic experiences. Mostly, participants had been in Australia less than six 


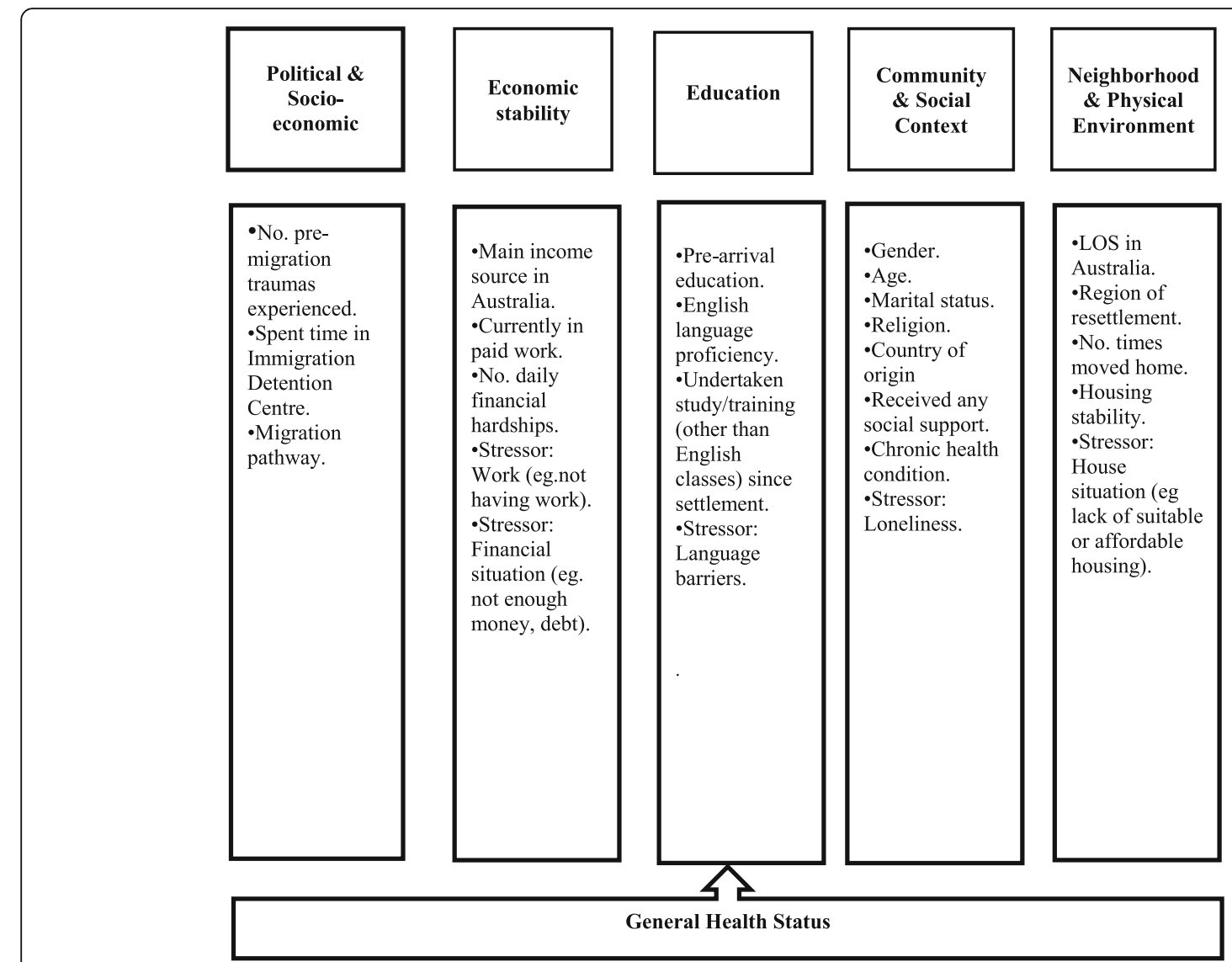

Fig. 1 Conceptual framework for the social determinants of health in resettled refugee populations (authors' own figure)

months $(82.1 \%)$ and were living in metropolitan cities (90.7\%). There was little financial stability with high unemployment (90.7\%); high dependency on government income support $(88.0 \%)$ and at least one financial daily hardship (42.3\%). Only $9.3 \%$ were in paid employment at baseline. Stress caused by not having work, stable housing and language barriers was reported by 33.0, 28.1 and $56.0 \%$ of participants, respectively. Having a 'chronic' health condition was reported by $23.0 \%$ of participants at baseline. See Table 1.

\section{GLMM results}

Table 2 provides the results of generalised linear mixed effect models, with general health as the outcome variable and pre- and post-migration factors as the predictor variables across the three years of follow-up. Individual characteristics, such as being female, older in age, originating from the Middle East and having a university qualification were significant positive predictors of poorer general health. For example, our results show that over the three years of follow up, females have 2.02 the odds of reporting 'Fair-Very Poor' health compared with males. In terms of post-migration stressors, several economic factors were associated with the reporting of
'Fair-Very Poor' health among this refugee population. An increasing number of daily financial stressors was significantly associated with higher odds of reporting poorer health. For example, those with 3-6 daily financial hardships were at increased risk for reporting poorer general health than those without any daily financial stressors. "Other" main income source (ie. spouse/partner/parent's income) was also positively associated with poorer health (OR: 3.25, 95\% CI: 0.013).

Not having a chronic disability/injury or condition was associated with reporting 'better' general health (OR: 0.15; 95\% CI 0.09-1.04) among this refugee population. That is, those without a chronic health condition have 0.15 the odds of reporting 'Fair-Very Poor' health compared with those with a chronic health condition. Another way to interpret the results is that those who do not have a chronic health condition are $85 \%$ less likely to report poorer general health. We found no significant association between the health outcomes and duration of stay in Australia, education, accommodation, social support or discrimination.

\section{Self-rated general health}

The mean general health prevalence among humanitarian refugees was calculated in two ways: (1) using BNLA 
Table 1 Baseline characteristics of humanitarian refugees in the Building A New Life in Australia project, 2013-14 (weighted data)

\begin{tabular}{|c|c|c|c|}
\hline Characteristic & Description & Response & Total $(n=2399)^{*}$ \\
\hline Age, mean (years) & Age & - & $35.5(13.9)$ \\
\hline \multirow[t]{7}{*}{ Age category (years) } & \multirow[t]{7}{*}{ Age category } & $14-18$ & $218(9.1 \%)$ \\
\hline & & $19-25$ & $523(21.8 \%)$ \\
\hline & & $26-35$ & $696(29.0 \%)$ \\
\hline & & $36-45$ & $475(19.8 \%)$ \\
\hline & & $46-55$ & $272(11.4 \%)$ \\
\hline & & $56-65$ & $143(6.0 \%)$ \\
\hline & & $65+$ & $69(2.9 \%)$ \\
\hline \multirow[t]{2}{*}{ Gender } & \multirow[t]{2}{*}{ Gender } & Male & 1295 (54.0\%) \\
\hline & & Female & $1103(46.0 \%)$ \\
\hline \multirow[t]{2}{*}{ Married or partnered } & \multirow[t]{2}{*}{ Married or has partner } & Yes & $1375(61.0 \%)$ \\
\hline & & No & 879 (39.0\%) \\
\hline \multirow[t]{5}{*}{ Region of birth } & \multirow{5}{*}{$\begin{array}{l}\text { Major groups based on the } \\
\text { Standard Australian Classification } \\
\text { of Countries major groups }\end{array}$} & Middle East & $1073(45.0 \%)$ \\
\hline & & Central Asia & $482(20.2 \%)$ \\
\hline & & Southern Asia & $332(14.0 \%)$ \\
\hline & & South-East Asia & $226(9.5 \%)$ \\
\hline & & Africa & $273(11.4 \%)$ \\
\hline \multirow[t]{5}{*}{ Education level, pre-arrival } & \multirow{5}{*}{$\begin{array}{l}\text { Highest level of education achieved } \\
\text { prior to arrival in Australia }\end{array}$} & Never attended school & $350(14.8 \%)$ \\
\hline & & $<6$ years of school & $419(17.7 \%)$ \\
\hline & & $6-12$ years of school & $1171(49.4 \%)$ \\
\hline & & Trade or tech qualification & $142(6.0 \%)$ \\
\hline & & University degree & $87(12.1 \%)$ \\
\hline \multirow[t]{2}{*}{ English speaking proficiency } & \multirow[t]{2}{*}{ Currently understands spoken English } & Very well/well & $793(33.6 \%)$ \\
\hline & & Not well/not at all & $1571(66.4 \%)$ \\
\hline \multirow[t]{3}{*}{ No. pre-migration trauma experienced } & \multirow{3}{*}{$\begin{array}{l}\text { Number of pre-migration traumas } \\
\text { experienced }\end{array}$} & None & $248(11.2 \%)$ \\
\hline & & $1-2$ & $1286(57.9 \%)$ \\
\hline & & 3 or more & $689(31.0 \%)$ \\
\hline \multirow[t]{2}{*}{ Migration pathway } & \multirow{2}{*}{$\begin{array}{l}\text { Arrived in Australia via onshore }{ }^{\dagger} \text { or } \\
\text { offshore migration pathway }{ }^{+\dagger}\end{array}$} & Onshore pathway & $458(19.1 \%)$ \\
\hline & & Offshore pathway & $1940(80.9 \%)$ \\
\hline \multirow{2}{*}{$\begin{array}{l}\text { Spent time in offshore Immigration } \\
\text { Detention Centre(s) }\end{array}$} & \multirow{2}{*}{$\begin{array}{l}\text { Spent time in offshore Immigration } \\
\text { Detention Centre(s) prior to resettlement }\end{array}$} & Yes & $202(8.6 \%)$ \\
\hline & & No & $2146(91.4 \%)$ \\
\hline \multirow[t]{4}{*}{ Duration of stay in Australia } & \multirow[t]{4}{*}{ Length of time spent in Australia } & Less than 1 year & $1968(82.1 \%)$ \\
\hline & & $1-2$ years & $271(11.3 \%)$ \\
\hline & & $2-3$ years & $76(3.2 \%)$ \\
\hline & & More than 3 years & $84(3.5 \%)$ \\
\hline \multirow[t]{3}{*}{ Region of settlement in Australia } & \multirow[t]{3}{*}{ Region of settlement in Australia } & Metropolitan cities & $2174(90.7 \%)$ \\
\hline & & Inner regional Australia & $184(7.7 \%)$ \\
\hline & & Outer regional Australia & $39(1.7 \%)$ \\
\hline \multirow[t]{2}{*}{ Currently in paid employment } & \multirow{2}{*}{$\begin{array}{l}\text { Currently in paid employment in } \\
\text { Australia }\end{array}$} & Yes & $143(9.3 \%)$ \\
\hline & & No & $1403(90.7 \%)$ \\
\hline \multirow[t]{3}{*}{ Main income source in Australia } & Main source of income in Australia & Own salary/income & $180(7.7 \%)$ \\
\hline & & Government support & $2059(88.0 \%)$ \\
\hline & & Other & $101(4.3 \%)$ \\
\hline No. daily financial hardships & Number of daily financial hardships & None & $1307(57.8 \%)$ \\
\hline
\end{tabular}


Table 1 Baseline characteristics of humanitarian refugees in the Building A New Life in Australia project, $2013-14$ (weighted data) (Continued)

\begin{tabular}{|c|c|c|c|}
\hline Characteristic & Description & Response & Total $(n=2399)^{*}$ \\
\hline & experienced in Australia & $1-2$ & $654(29.0 \%)$ \\
\hline & & $3-4$ & $240(10.7 \%)$ \\
\hline & & $5-6$ & $59(2.6 \%)$ \\
\hline \multirow{2}{*}{$\begin{array}{l}\text { Undertaken further study/training } \\
\text { in Australia }\end{array}$} & \multirow{2}{*}{$\begin{array}{l}\text { Undertaken study or job training in } \\
\text { Australia, other than English language } \\
\text { classes }\end{array}$} & Yes & $410(17.4 \%)$ \\
\hline & & No & $1956(82.6 \%)$ \\
\hline \multirow[t]{2}{*}{ Stress-language barriers } & \multirow{2}{*}{$\begin{array}{l}\text { Language barriers as main source of } \\
\text { stress in Australia }\end{array}$} & Yes & 1279 (56.0\%) \\
\hline & & No & 1009 (44.0\%) \\
\hline \multirow[t]{2}{*}{ Stress-work situation } & \multirow{2}{*}{$\begin{array}{l}\text { Work situation as main source of stress } \\
\text { in Australia (eg unemployment, hours } \\
\text { of work, conditions) }\end{array}$} & Yes & $754(33.0 \%)$ \\
\hline & & No & $1534(67.0 \%)$ \\
\hline \multirow[t]{2}{*}{ Stress-housing situation } & \multirow{2}{*}{$\begin{array}{l}\text { Work situation as main source of stress } \\
\text { in Australia (eg lack of suitable or } \\
\text { affordable housing) }\end{array}$} & Yes & $659(28.1 \%)$ \\
\hline & & No & 1629 (71.2\%) \\
\hline \multirow[t]{2}{*}{ Stress-loneliness } & \multirow{2}{*}{$\begin{array}{l}\text { Loneliness as main source of stress } \\
\text { in Australia }\end{array}$} & Yes & $363(15.9 \%)$ \\
\hline & & No & $1926(84.1 \%)$ \\
\hline \multirow[t]{2}{*}{ Received any social support } & \multirow{2}{*}{$\begin{array}{l}\text { Received any religious, like ethnic or } \\
\text { community support in Australia }\end{array}$} & Yes & $859(35.8 \%)$ \\
\hline & & No & $1539(64.2 \%)$ \\
\hline \multirow{2}{*}{$\begin{array}{l}\text { Has long term disability, injury } \\
\text { or health condition }\end{array}$} & \multirow{2}{*}{$\begin{array}{l}\text { Presence of absence of long-term health } \\
\text { condition that has lasted or is likely to } \\
\text { last }>12 \text { mths }\end{array}$} & Yes & $859(35.8 \%)$ \\
\hline & & No & $1539(64.2 \%)$ \\
\hline
\end{tabular}

*Data are provided as $\mathrm{n}(\%)$ or mean (SD)

${ }^{\dagger}$ Onshore pathway is available to those who wish to apply for asylum after arrival in Australia as an unauthorised maritime arrival or holder of valid visa (eg. tourist)

${ }^{++}$Offshore pathway is available to those who may be eligible for resettlement to Australia, such as those identified by the UNHCR or those eligible for sponsorship to Australia

sample data, and (2) using the final model adjusting for model independent variables. Both methods used the provided sample weights. Both methods showed no significant changes in general health over time. See Table 3.

Using BNLA sample data, 35.7\% (33.8-37.7\%) of participants reported "Fair-Very Poor" self-rated health at baseline (see Table 2). At Wave 2, 691 (36.8\%) participants' self-reported 'Fair-Very Poor' general health (95\% CI 34.6-39.0\%) and 685 (39.7\%) had 'Fair-Very Poor' general health (95\% CI 37.4-42.0\%) at Wave 3.

Table 3 shows the prevalence estimates of "Fair-Very Poor" self-rated health calculated using the final GLMM model. In Wave 1, the prevalence for 'Fair-Very Poor' general health was $34.6 \%$. In Waves 2 and 3 the prevalence was 34.0 and $33.4 \%$, respectively. This shows that the prevalence of 'Fair-Very Poor' general health remained high across the 3 years but did not decrease or increase substantially over time. The significance of change in 'Fair-Very Poor' general health over time was also examined using the final GLMM model.

Between Waves 1 and 2, there was no significant decrease in the prevalence of "Fair-Very Poor" self-rated health $(p=0.779)$. See Table 3. Waves 1 and 2 saw no significant differences in "Fair-Very Poor" self-rated health $(p=0.802)$. There was also no significant overall decrease between Wave 1 and 3 for "Fair-Very Poor" self-rated health $(p=0.512)$. Therefore, the results indicate that there was no significant change in "Fair-Very Poor" self-rated health over the three years of follow-up. In summary, on a population level, the point prevalence of "Fair-Very Poor" self-rated health remained high, but no overall significant increase (or decrease) in "Fair-Very Poor" self-rated health was seen over time.

\section{Discussion}

This study, to our knowledge, is the first to examine the long-term general health status of resettled adult humanitarian refugees in Australia. In doing so, we provide novel insights into the refugee experience of health as they adjust to conditions in a new society, including our revelation of a sustained and high prevalence of poorer general health among refugees over time. In addition, the factors associated with this poorer general health have not previously been reported in a longitudinal study of Australian humanitarian refugees. Consequently, this knowledge has the potential to build an evidence base for development of improved settlement policies and programs, such as targeted health care and health promotion [3].

The high and sustained prevalence of poorer general health suggests that our refugee population bears a 
Table 2 Results from generalised linear mixed models using self-rated general health in past 4 weeks with "Excellent-Good" and "Fair-Very Poor" the outcome. OR-odds ratio; $\mathrm{p}=\mathrm{p}$-value; $\mathrm{Cl}=$ confidence interval

\begin{tabular}{|c|c|c|c|c|}
\hline \multirow[t]{2}{*}{ Variable } & \multirow[t]{2}{*}{ Response } & \multicolumn{3}{|c|}{ General Health } \\
\hline & & $\overline{O R}$ & $p$ & $95 \% \mathrm{Cl}$ \\
\hline \multirow[t]{2}{*}{ Gender } & Male & - & - & - \\
\hline & Female & 2.02 & 0.000 & $(1.51-2.71)$ \\
\hline \multirow[t]{6}{*}{ Age Group (years) } & $18-25$ & - & - & - \\
\hline & $26-35$ & 1.71 & 0.032 & $(1.05-2.78)$ \\
\hline & $36-45$ & 3.45 & 0.000 & $(2.13-5.60)$ \\
\hline & $46-55$ & 6.91 & 0.000 & $(3.83-5.50)$ \\
\hline & $56-65$ & 9.86 & 0.000 & $(5.00-9.41)$ \\
\hline & $65+$ & 8.32 & 0.000 & $(3.31-10.9)$ \\
\hline \multirow[t]{5}{*}{ Region of Birth } & Middle East & - & - & - \\
\hline & Africa & 0.39 & 0.000 & $(0.17-0.56)$ \\
\hline & Central Asia & 0.39 & 0.000 & $(0.26-0.58)$ \\
\hline & South-East Asia & 0.92 & 0.802 & $(0.50-1.70)$ \\
\hline & Southern Asia & 1.08 & 0.755 & $(0.65-1.81)$ \\
\hline \multirow[t]{5}{*}{ Pre-arrival education } & No schooling & - & - & - \\
\hline & $\leq 6$ years of schooling & 1.15 & 0.545 & $(0.73-1.82)$ \\
\hline & $6-12$ years of schooling & 0.70 & 0.118 & $(0.45-1.09)$ \\
\hline & Trade or technical qualification & 0.70 & 0.308 & $(0.36-1.38)$ \\
\hline & University degree & 0.50 & 0.021 & $(0.28-0.90)$ \\
\hline \multirow[t]{3}{*}{ Main income source in Australia } & Own salary or wage & - & - & - \\
\hline & Government support & 1.50 & 0.156 & $(0.86-2.65)$ \\
\hline & Other & 3.25 & 0.013 & $(1.27-8.30)$ \\
\hline \multirow[t]{3}{*}{ No. daily financial hardships } & 0 & - & - & - \\
\hline & $1-2$ & 1.75 & 0.002 & $(1.23-2.51)$ \\
\hline & $3-6$ & 3.01 & 0.001 & $(1.60-5.70)$ \\
\hline \multirow[t]{2}{*}{ Has long term disability, injury or health condition } & Yes & - & - & - \\
\hline & No & 0.15 & 0.000 & $(0.09-1.04)$ \\
\hline
\end{tabular}

substantial health burden compared with the wider Australian population. For example, by comparison, $4 \%$ of the Australian population self-report poor general health and $10 \%$ of Australians rate their general health as fair [23]. Factors associated with refugee status are plausible explanations for this observed health disparity. For example, there is evidence to suggest that refugees in Australia experience multilevel barriers to the healthcare and this may be affecting their overall health outcomes [24, 25]. Although Australia provides generous support to humanitarian entrants, our results suggest that existing policies on refugee resettlement have been less effective than desired on improving the health of Australian refugees.

Consistent with other research is our finding of an association between post-settlement economic stressors

Table 3 Mean general health prevalence among humanitarian refugees in the BNLA project calculated two ways using: (1) sample data; and (2) final model adjusting for model independent variables. Both methods used the provided sample weights. $(n)^{n}=$ Number provided in the sample calculation only

\begin{tabular}{|c|c|c|c|c|c|c|c|}
\hline \multicolumn{2}{|l|}{ General Health } & \multicolumn{2}{|l|}{ Wave 1} & \multicolumn{2}{|l|}{ Wave 2} & \multicolumn{2}{|l|}{ Wave 3} \\
\hline Fair-Very Poor & Weights applied & $\%(n)^{n}$ & $95 \% \mathrm{Cl}$ & $\%(n)^{n}$ & $95 \% \mathrm{Cl}$ & $\%(n)^{n}$ & $95 \% \mathrm{Cl}$ \\
\hline Mean calculated from sample & Yes & $35.7 \%(805)$ & $33.8-37.7 \%$ & $36.8 \%(691)$ & $34.6-39.0 \%$ & $39.7 \%(685)$ & $37.4-42.0 \%$ \\
\hline Mean calculated for model variables & Yes & 34.6 & & 34.0 & & 33.4 & \\
\hline
\end{tabular}

NOTE: No significant differences between waves as suggested by $95 \%$ confidence intervals and this was confirmed using $z$-tests: Waves $1-2$ difference $z$ statistic $=0.28$, $p=0.779$; Waves $2-3$ difference $z$-statistic $=0.25 ; p=0.802$; and Waves1 -3 difference $z$-statistic $=0.66 ; p=0.51$ 
and poorer general health [13, 26, 27]. We also confirm a strong dose-response like relationship with daily financial hardships and poorer general health, however, this relationship has only been shown previously in crosssectional studies of refugee populations [26]. Unemployment was not a significant predictor of poorer general health, which suggests that it is the financial consequences of unemployment which may be more important for the long-term general health among our refugee population. Nowhere in the literature has an association between main income and poorer general health been reported previously and our finding that 'other' main income source (ie. spouse/partner/parent's income) is interesting because humanitarian refugees in Australia can access welfare payments and employment [28].

Although the association found between the presence of chronic health conditions and poorer health among our refugee population is not unexpected [27, 29], we are the first to report this association in a longitudinal study of resettling refugees. Not only do we provide evidence of chronic disease prevalence among newly arrived refugees, but we also demonstrate its impact on long-term health. Our finding also confirms the reports of the reports of the rising prevalence of chronic health conditions in refugees' regions of origin, particularly the Middle East [30]. Resettling refugees are potentially susceptible to the development of chronic disease due to host nation stressors as well as the adoption of a less health western diet and a more sedentary lifestyle and resettlement stressors [31]. A number of refugee studies have reported that resettlement has been found to increase the risk of obesity and non-communicable diseases, including diabetes and hypertension, due to weight gain and resettlement stressors [32-34]. Left unmanaged, the chronic health burden among refugee populations is also likely to impact their resettlement success.

Female gender, older in age, Middle Eastern origin and education level were all found to be risk factor for poorer general health, confirming previous cross-sectional studies of refugee populations [35-37]. Previous research has shown that older refugees are particularly vulnerable to physical deterioration post-settlement [35] and there is solid support that poorer health has a higher prevalence among women [8]. Having a university degree (pre-migration) was significantly and negatively associated with long-term self-rated general health among refugees [35, 37]. Among refugee populations, it has been shown that those with lower levels of education are less likely to seek healthcare, participate in health promoting and disease promoting activities [38]. Therefore, it may be that those with a university qualification possess the skills to achieve a higher level of self-sufficiency with regards to their long-term health. That is, they may know their health needs better and are able to access health services better. Given that many refugees subgroups, such as female Afghanis, have little to no schooling [39], our result highlights the importance of understanding the education needs of resetting refugees as a way of offsetting adverse health outcomes.

\section{Conclusion}

Our study provides an insight into the long-term general health of resettling refugees in Australia and its associated risk factors. Our results highlight a pattern of additional health needs existing within this refugee population. The risk-factors for poorer self-rated health give shape to future interventions or policy responses to help in the health and well-being of this highly vulnerable group.

\section{Limitations}

There are several methodological limitations in this study. Retrospective reporting and reliance on selfreporting may run a risk of not remembering or misrepresenting the events and non-accurate measurement of symptoms [40], presenting a risk of recall bias, personal interpretations across languages and cultures. Further, the BNLA study collected information that is more comprehensive from principal visa applicants than from secondary applicants, which constrains the depth and breadth of findings of the study. Alternating face-to-face with telephone interviews may have introduced some inconsistencies across waves in that some respondents may have answered some questions differently depending on the interview style. Despite these limitations, this study has contributed to the literature by providing information about the migration experiences of a large and ethnically diverse cohort of refugees during their first three years of resettlement in Australia and the impact of such experiences on general health.

\section{Implications of the findings}

Our results show that there is persisting high prevalence of poorer general health among adult refugees across the first three years of their resettlement in Australia. This finding suggests unmet health needs which may be compounded by the challenges of resettlement in a new society. This result highlights the need for increased clinical awareness of this sustained health burden to help inform and prepare refugee health care and settlement service providers. It also underscores the importance for health professionals to consider broad health issues among refugee populations and highlights the potential value of the Australian Medical Benefit Schedule subsidy of refugee health assessments for recent refugee arrivals [41]. The association between poorer general health and settlement economic stressors highlight the importance of understanding and eliminating the barriers, which 
lead to the high rates of unemployment among refugees, as a way of preventing negative health consequences. Qualitative research into the barriers to employment, using the perspectives of refugees themselves; would be a valuable addition to the current knowledge gap. This study also highlighted that attention should be given to assessing the specific needs of groups of refugees based on their demographic characteristics; for example, older, Middle Eastern females. Given the vulnerabilities of these groups, sustained targeted interventions upon entry to Australia would be beneficial to offset any further decline in health.

\section{Additional file}

Additional file 1: Monash University Human Research Ethics Committee exemption letter regarding the use of the 'Building A New Life in Australia' data sets. (DOCX $27 \mathrm{~kb}$ )

\section{Abbreviations}

AlHW: Australian Institute of Health and Wellbeing; BNLA: Building A New Life In Australia; Cl: confidence interval; DSS: Department of Social Services; GLMM: Generalized linear mixed modelling; MU: Migrating Units; OR: odds ratio; PA: Principal applicants; SA: Secondary applicants; SF-36: 36-Item Short Form Health Survey; SRGH: Self-rated general health; UNHCR: United Nations High Commissioner for Refugees

\section{Acknowledgements}

Not applicable.

\section{Authors' contributions}

$A D$, JE and GR obtained access to the first three waves of data from the 'Building a New Life in Australia' project. AD and JE developed the analytical strategy. AD and MK designed the social determinants of health model to guide the variable selection process. GR reviewed all aspects of the study design. AD did statistical analysis and drafted the manuscript. All authors contributed to the data interpretation, manuscript writing, and final approval of the manuscript.

\section{Funding}

No funding was secured for this study.

\section{Availability of data and materials}

All datasets used in this study are available from the Australian Government's Department of Social Services at the website: https://www.dss.gov.au/ national-centre-for-longitudinal-data-ncld/access-to-dss-longitudinal-datasets.

\section{Ethics approval and consent to participate}

Ethics exemption to use the BNLA data was granted by the Monash University Research Ethics Committee.

\section{Consent for publication}

Not required as data used in this study was de-identified.

\section{Competing interests}

The authors declare that they have no competing interests.

\section{Author details}

'Department of General Practice, School of Primary Health Care, Monash University, Melbourne, Australia. ${ }^{2}$ Southern Synergy, School of Clinical Sciences at Monash Health, Monash University, Melbourne, Australia.
Received: 11 March 2019 Accepted: 13 August 2019

Published online: 22 August 2019

\section{References}

1. United Nations High Commissioner for Refugees. Global Trends, 2017. Geneva. URL: http://www.unhcr.org/globaltrends2017. Accessed 25 July 2018

2. Spinks $\mathrm{H}$, Barker $\mathrm{C}$. immigration and border protection overview. Budget review 2016-17 index. Parliament of Australia URL: https://www.aph.gov.au/ About_Parliament/Parliamentary_Departments/Parliamentary_Library/pubs/ rp/BudgetReview201617/Immigration. Accessed 19 Aug 2018.

3. Dowling A, Enticott J, Russell G. Measuring self-rated health status among resettled adult refugee populations to inform practice and policy - a scoping review. BMC Health Serv Res. 2017;17(1):1-9.

4. Lau W, Silove D, Edwards B, Forbes D, Bryant R, McFarlane A, Hadzi-Pavlovic D, Steel Z, Nickerson A, Van Hooff M, Felmingham K, Cowlishaw S, Alkemade N, Dzenana K, O'Donnell M. Adjustment of refugee children and adolescents in Australia: outcomes from wave three of the Building a New Life in Australia study. BMC Med. 2018;16(1):1-10.

5. Fazel M, Wheeler J, Danesh J. Prevalence of serious mental disorder in 7000 refugees resettled in western countries: a systematic review. Lancet. 2005; 365:1309-14.

6. Porter M, Haslam N. Pre-displacement and post-displacement factors associated with mental health of refugees and internally displaced persons: a meta-analysis. JAMA. 2005;294(5):602-12.

7. Silove D, Steel Z, Suslijk I, Frommer N, Loneragan C, Chey T, Brooks R, le Touze D, Ceollo M, Smith M, Harris E, Bryant R. The impact of the refugee decision on the trajectory of PTSD, anxiety, and depressive symptoms among asylum seekers: a longitudinal study. Am J Disaster Med. 2007;2(6): 321-9.

8. Gerritsen A, Bramsen I, Deville W, Willigen L, Hovens J, Ploeg H. Physical and mental health of afghan, Iranian and Somali asylum seekers and refugees living in the Netherlands. Soc Psych Epid. 2006:41:18-26.

9. Steel Z, Silove D, Giao N, Phan T, Chey T, Whelan A, Bauman A, Bryant R. International and indigenous diagnoses of mental disorder among Vietnamese living in Vietnam and Australia. Br J Psychiatry. 2009;194(4):326-33.

10. DeSalvo K, Bloser M, Renolds K, Jiang H, Munter P. Mortality prediction with a single general self-rated health question. A meta-analysis. J Gen Intern Med. 2006;21(3):267-75.

11. Stanojevic J, Sauliune S, Sumskas L, Birt C, Kersnik J. Determinants of selfrated health in elderly populations in urban areas in Slovenia, Lithuania, and UK: findings of the EURO-URHIS 2 survey. Eur J Public Health. 2017; 27(suppl_2):74-9.

12. Falk H, Skoog I, Johansson L, Guerchet M, Mayston R, Horder H, Prince M, Prina M. Self-rated health and its association with mortality in older adults in China, India, and Latin America - a 10/66 dementia research group study. Age Ageing. 2017;46(6):932-9.

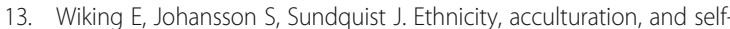
reported health. A population-based study among immigrants from Poland, Turkey, and Iran in Sweden. J Epidemiol Community Health. 2004;58(7):574-82.

14. Chen W, Ling L, Renzaho A. Building a new life in Australia: an analysis of the first wave of the longitudinal study of humanitarian migrants in Australia to assess the association between social integration and self-rated health. BMJ Open. 2017a;7(3):15-23.

15. Chen W, Hall B, Ling $L$, Renzaho A. Pre-migration and post-migration factors associated with mental health in humanitarian migrants in Australia and the moderation effect of post-migration stressors: findings from the first wave data of the BNLA cohort study. Lancet Psychiatry. 2017b;4(3):218-29.

16. Bryant $R$, Edwards $B$, Creamer $M$, et al. The effect of post-traumatic stress disorder on refugees' parenting and their children's mental health: a cohort study. Lancet Public Health. 2018;3(5):e249-58.

17. Cooper S, Enticott J, Shawyer F \& Meadows G. Determinants of Mental Illness Among Humanitarian Migrants: Longitudinal Analysis of Findings From the First Three Waves of a Large Cohort Study. Frontiers in Psychiatry. 2019;10(4):15-21.

18. De Maio J, Silbert M, Jenkinson R, Smart D. Building a new life in Australia: introducing the longitudinal study of humanitarian migrants. Fam Matters 2014;94:5-14.

19. Cross-Denney B, Robinson M. Using the social determinants of health as a framework to examine and address predictors of depression in later life. Ageing Int. 2017;42(4):393-412. 
20. Ware J, Sherbourne C. The MOS 36-item short-form health survey (SF-36): I. conceptual framework and item selection. Med Care. 1992;30:473-83.

21. Erriksson I, Unden A, Elofsson S. Self-rated health. Comparisons between different measures. Results from a population study. Int J Epidemiol. 2001; 30(2):326-33.

22. StataCorp S. Stata statistical software: release 14. SE 14.2 ed. College Station, TX: StataCorp LP; 2015

23. Australian Institute of Health and Welfare. Chronic disease. URL: https:// www.aihw.gov.au/reports-data/health-conditions-disability-deaths/chronicdisease/overview. Accessed 1 Jan 2019.

24. Taylor J, Haintz G. Influence of the social determinants of health on access to healthcare services among refugees in Australia. Australian Journal of Primary Health. 2017;24(1)14-28.

25. Hadgkiss E. RenzahoA. The physical health status, service utilisation and barriers to accessing care for asylum seekers residing in the community: a systematic review of the literature. Aust Health Rev. 2014;38(2):142-59.

26. Maximova $\mathrm{K}$, Krahn $\mathrm{H}$. Health status of refugees settled in Alberta: changes since arrival. Can J Public Health. 2010;101(4):322-6.

27. Wang B, Yu S, Jin-Won N, Kwon Y. Factors associated with self-rated health among north Korean defectors residing in South Korea. BMC Public Health. 2014;14:999-105.

28. Department of Social Services, Australian Government. Settlement Services for Humanitarian Entrants. URL: https://www.dss.gov.au/settlement-andmulticultural-affairs/publications/settlement-services-for-humanitarianentrants. Accessed 20 Oct 2018.

29. Yoon I, Kim S. Health and medical are of north Korean defectors in South Korea. Health Soc Sci. 2005;17:149-82.

30. Lopez A, Mathers C, Ezzati M, Jamison D, Murray C. Global and regional burden of disease and risk factors, 2001: systematic analysis of population health data. Lancet. 2006;367(9524):747-53.

31. Yun K, Hebrank K, Graber L, Sullivan M, Chen I, Gupta J. High prevalence of chronic non-communicable conditions among adult refugees: implications for practice and policy. J Community Health. 2012;37(5):1110-8.

32. Palinkas LA, Pickwell SM. Acculturation as a risk factor for chronic disease among Cambodian refugees in the United States. Soc Sci Med. 1995;40(12): 1643-53.

33. Kearns R, Woodland L. Overweight and obesity among adolescent refugees and migrants arriving in Australia: A review of the literature, South Eastern Research Collaboration Hub, part of the Centre for Primary Health Care and Equity, UNSW Sydney (2019). Sydney. URL: https://apo.org.au/sites/default/files/ resource-files/2019/02/apo-nid222586-1335536.pdf. Accessed 19 May 2019.

34. Yanni EA, Naoum M, Odeh N, Han P, Coleman M, Burke H. The health profile and chronic diseases comorbidities of US-bound Iraqi refugees screened by the International Organization for Migration in Jordan: 2007-2009. J Immigr Minor Health. 2013;15(1):1-9. https://doi.org/10.1007/s10903-012-9578-6.

35. Jamil H, Barkho E, Broadbridge C, Ventimiglia M, Arnetz J, Lami F, Arnetz B. Self-rated health and medical conditions in refugees and immigrants from the same country of origin. Iraqi J Med Sci. 2015;13(2):108-19.

36. Steel Z, Silove D, Phan T, Bauman A. Long-term effect of psychological trauma on the mental health of Vietnamese refugees resettled in Australia: a population-based study. Lancet. 2002;360(9339):1056-62.

37. Ng E, Pottie K, Spitzer D. Official language proficiency and self-reported health among immigrants to Canada. Health Rep. 2011;22(4):15-23.

38. Wangdahl J, Lytsy P, Martensson L, Westerling R. Poor health and refraining from seeking healthcare are associated with comprehensive health literacy among refugees: a Swedish cross-sectional study. Int J Public Health. 2018 63(3):409-19.

39. UNESCO Education for All Global Monitoring Report 2011 URL: https:/en. unesco.org/gem-report/sites/gem-report/files/gmr2011-gender-overview.pdf Accessed 20 May 2019

40. Kessler R, Barker P, Colpe L, Epstein F, Gfroerer J, Hiripi E, Howes M, Normand S, Manderscheid R, Walters E, Zaslavsky A. Screening for serious mental illness in the general population. Arch Gen Psychiatry. 2003;60(2):184-9.

41. Department of Health. Medicare Benefits Schedule (MBS) Health assessment for refugees and other humanitarian entrants. URL: http://www.health.gov.au/ internet/main/publishing.nsf/Content/mbsprimarycare_mbsitem_refugees. Accessed 2 Jan 2019.

\section{Publisher's Note}

Springer Nature remains neutral with regard to jurisdictional claims in published maps and institutional affiliations.

Ready to submit your research? Choose BMC and benefit from:

- fast, convenient online submission

- thorough peer review by experienced researchers in your field

- rapid publication on acceptance

- support for research data, including large and complex data types

- gold Open Access which fosters wider collaboration and increased citations

- maximum visibility for your research: over $100 \mathrm{M}$ website views per year

At BMC, research is always in progress.

Learn more biomedcentral.com/submissions 